\title{
UM COMERCIANTE DO CICLO DO AÇÚCAR PAULISTA: ANTÔNIO DA SILVA PRADO $(1817-1829)(*)$.
}

\author{
MARIA THEREZA SCHORER PETRONE \\ Professôra-Assistente da Cadeira de História da Civili- \\ zaçáo Brasileira da Faculdade de Filosofia, Ciências e \\ Letras de Universldade de São Paulo.
}

A documentação particular é de suma importância para o historiador, pois dela se colhem com mais facilidade certos pormenores necessários à reconstrução do passado. A documentação oficial, por exemplo, raramente nos informa satisfatòriamente a respeito dos múltiplos aspectos da comercialização do açúcar, durante o período em que a economia paulista dependia da cana (1765-1851). Para o caso paulista, existe a correspondência de Antônio da Silva Prado, grande comerciante que, durante certo tempo, se interessou em negócios de açúcar. Acreditamos tratar-se de uma documentação, se não única, pelo menos bastante rara no Brasil, e capaz de permitir, em tôdas as minúcias, a reconstituição de um aspecto de nossa História Econômica, restrito, embora, a breve período. As cartas que nos interessam vão de 1817 a 1822 , reiniciando-se em 1825, para chegar até 1829 (1). Trata-se de poucos anos, mas bem representativos, pois se situam numa fase de amplos progressos para a lavoura canavieira de São Paulo.

(*). - Este trabalho foi apresentado como apêndice da Tese de Doutoramento A Lavoura Canavieira em Sấo Paulo: Expansão e Declinio (1765-1851), defendida em agôsto de 1964 na Faculdade de Filosofia, Ciências e Letras da Universidade de Sáo Faulo (Nota da Redação).

(1). - A Coleção Antônio da Silva Prado está conservada no Arquivo do Instituto Histórico e Geográfico de São Paulo. Trata-se de 27 volumes manuscritos que, além de contas correntes e do Diário Geral, contém copiadores de cartas que são extremamente interessantes, não só para o - nosso assunto, mas também para outros aspectos da vida econômica de Sāo Paulo. Infelizmente não foram conservados todos os copiadores de cartas do futuro Earăo de Iguape. Os copiadores iniciam-se em 1817 e interrompem-se em 1822, para reiniciar em 1825 e interromperem-se em 1829, só começando de nôvo em 1850. Da numeração dos copiadores, entretanto, depreende-se que Antônio da Silva Prado os tinha para todos os anos. O extravio é lamentável, pois, certamente, poderiam fornecer informaçóes preciosas para os anos em que floresceu a indústria acucareira. 
A correspondência de Antônio da Silva Prado com senhores de engenho, fornecedores do açúcar, com os condutores do produto, com os correspondentes em Santos, na Bahia e no Rio de Janeiro, fornece-nos uma série de dados inestimáveis. Mostra-nos uma organização complexa, da qual o capitalista é figura central manejando todos os outros integrantes, segundo as conveniências de seu negócio. Nessa organização que criou, aparece o senhor de engenho que the vende a safra. Às vêzes, aparece o intermediário, que procura entrar em contato com o senhor de engenho em nome de Antônio da Silva Prado e se encarrega de arranjar os condutores de tropa para transportar o produto até Santos. Os mesmos condutores são, por sua vez, outra peça dessa organização. Em Santos o açúcar é recebido por um correspondente que o beneficia e embarca. O comandante do barco, estipulando o frete, também é elemento importante nessa cadeia. $O$ último elemento é o correspondente no pôrto de destino, geralmente no Rio de Janeiro, às vêzes, a Bahia. Na realidade a correspondência mostra o funcionamento do mecanismo da comercialização do açúcar; como e quando é comprado no engenho, seu preço, a condução do produto até Santos, o beneficiamento, encaixamento e preço naquele pôrto, o embarque, o custo do frete para o Rio de Janeiro, a venda, etc.

Lamentamos, apenas, que não tenha chegado até nós tôda a correspondência de Antônio da Silva Prado, mas, apesar de se abrangerem poucos anos, as informações que podemos tirar de suas cartas dão uma visão de como teria sido o negócio do açúcar em São Paulo. Isso, principalmente, porque as cartas conservadas mostram um ciclo fechado - do início de sua atividade nesse setor, até 1821 quando começava desinteressar-se do assunto, "cansado em lutar com êste negócio há 5 anos" (2).

Antônio da Silva Prado (1788-1875), paulista de nascimento começou sua carreira comercial, todavia, em Goiás e na Bahia (Caiteté). Regressou a São Paulo em 1816, onde, com os cabedais que trouxera, se tornara grande comerciante e arrematante da maior parte das rendas públicas nesta Capitania (3). Nos primeiros anos, depois de seu.regresso a São Paulo, interessou-se pelo comércio de açúcar, pois, assim como considerava que "pa hua terra adonde não há em que se ganhe dro não há remedio se não sujeitar-se a ser senhor de engenho" (4), também devia considerar o comércio de

(2). - Idem, 20, f. 91, carta de 5 de setembro de 1821.

(3). - Arrematou, por exemplo, entre outras, o Nôvo Impôsto de Sorocaba.

(4). - Col. A. S. P., 18, f. 69 vs., 1 de junho de 1817. Alguma colsa sôbre a personalidade de Antônio da Silva Prado pode ser vista em Castro, J. A. de Azevedo, Galeria dos Conservadores da Provincia de Sâo Paulo I. $O$ Barẫo de Iguape. 
ıçúcar uma das poucas atividades lucrativas além do arremate das rendas públicas.

O estudo do exemplo de Antônio da Silva Prado vale antes de mais nada, pela importância que teve no comércio de açúcar. Embora não tenhamos elementos para um estudo comparativo, acreditamos que o futuro Barão de Iguape, foi um comeciante de açúcar muito importante naqueles anos em São Paulo. Em 1819, por exemplo, escreve que o seu "empate este anno foi de 18000 a." de açúcar (5). Como veremos depois, é provável que tenha enviado mais açúcar com destino ao Rio de Janeiro. Segundo o "Mappa da Importação e Exportação do Pôrto de Santos no ano de 1818", a exportação de açúcar foi ao todo de 294.267 arrôbas (6). A contribuição de Antônio da Silva Prado, portanto, era apreciável, embora ambos os dados não se refiram ao mesmo ano. O fato de um único comerciante ter em mãos uma parte tão apreciável da exportação, não pode deixar de mostrar sua importância.

Antônio da Silva Prado não foi só comerciante de açúcar, em 1817 tornou-se também senhor de engenho. Explicou esta iniciativa ao irmão em Caiteté: "Estou em termos de meiar com o Paula em hum engenho q pertedemos levantar no Citio delle o ql vendeme a metade e eu entro com 12 escravos pa igualar outros tantos q'elle tem este negocio não hé bom porem $\mathrm{p}^{\mathrm{a}}$ hua terra adonde não há em q'se ganhe drơ não há remedio senão sujeitar-se a iso mmo o Thio Jordão tem interesse em 5 e todo saqui da Cide estão Snres de Engenho" (7). Trata-se do engenho da Vitória, em Jundiaí, que çomeçou a montar juntamente com Francisco de Paula Pedroso. As terras eram boas e o parceiro já tinha onze quartéis de cana plantada (8). Mandou comprar nove escravos no Rio de Janeiro, para juntá-los aos que possuia (9). Do Rio vieram também "o alambique e mais chapas de cobre" para o engenho (10). Este deveria começar a trabalhar em junho de 1818 (11). As obras, entretanto, não foram rápidas, e, em julho, Antônio da Silva Prado enviava para o engenho três tachos e três escumadeiras e recomendava ao sócio que mandasse fazer o reminhol de madeira e aprontasse as fornalhas "com toda a brevidade pois hé tempo de pegar a moer" (12).

\footnotetext{
(5). - Col. A. S. P., 19, f. 77 vs., 11 de abril de 1819.

(6). - Boletim do Departamento do Arquivo do Estado de Sáo Paulo. III, p. 40-58.

(7). - Col. A. S. P., 18, f. 69 vs., 11 de Junho de 1817.

(8). - Idem., 18, 1 de abril de 1817.

(9) . - Idem., 18, 1 . 68 vs., 11 de malo de 1817 e 31 de maio de 1817.

(10). - Idem., 18, 86 vs., 31 de janeiro de 1819 .

(11) - Ibidem.

(12). - Idem., 19, P. 116, 19 de julho de 1819
} 
$\mathrm{O}$ carpinteiro tinha prometido aprontar a obra até primeiro de julho de 1818 e Antônio da Silva Prado mandava avisá-lo de que todo o prejuizo, que porventura tivesse com o atraso, recairia sôbre êle (13). Pedia, igualmente, ao tio Eleutério da Silva Prado the arranjasse alguém para ir ao engenho a fim de fazer açúcar, mas não por duas patacas ao dia, pois isso levaria todo o rendimento do produto (14). Não existem informações sôbre a produção do $1^{\text {9 }}$ ano. Em agôsto de 1819, Antônio da Silva Prado pedia emprestado a um senhor de engenho um escravo banqueiro "pa ensinar fazer assucar no meu engenho estou pronto a lhe dar hum dos escravos melhores do $d^{\text {o }}$ meu engenho e $\mathrm{p}^{\mathrm{a}}$ refem deste, ou satisfazer-lhe o jornal q'for de seo arbitrio durante a safra" (15). No fim da safra o escravo emprestado foi elogiado por ter feito "excellete assucar e comportando-se com todo desvello" (16). Em fins de 1819, êle e o sócio aumentaram as terras comprando áreas contíguas (17). Esse empreendimento não foi, entretanto, vantajoso e, em setembro de 1820 , anuncia a venda de nove escravos e três negras com filhos para "extinguir o tal Engọ visto a conhecida negligência do sócio q'em pouco tempo será capaz dé reduzir a nada q'me obriga a tomar esta medida a fim de evitar o maior prejuizo q'ameaça" (18). Pela correspondência não se consegue saber se continuou a interessar-se na produção de açúcar (19). O que o ocupou vivamente foi o seu comércio, a que dedicou grande parte do seu trabalho.

\section{I). - A Compra da Safra de Açúcar.}

As compras de açúcar eram feitas, em geral, antes do comêço da safra. Antônio da Silva Prado escrevia, em outubro, que maio era o "tempo em que se vendem todas as safras e agora, já não há pr vender aqui pr Serra acima" açúcar nenhum (20). Quase sempre comprava a safra tôda de um engenho antes do início da colheita e da fabricação. Em 1817, ano em que se inicia nêsse comércio, comprara já em fevereiro o produto da futura safra (21). No ano

(13). - Idem., 19, f. 116, 19 de Julho de 1819.

(14). - Ibidem.

(15). - Idem., 19, f. 125, 17 de agôsto de 1819 .

(16). - Idem., 19, f. 205,14 de março de 1820 .

(17). - Idem., 19, ค. 165, 11 de junho de 1819.

(18) . - Idem., 19, f. 290,25 de setembro de 1820.

(19). - Mais tarde, em 1825, aparecem referências ao açúcar enviado a Antônio da "Silva Prado pelo seu antigo sócio Francisco de Paula Pedroso: Col. A. S. P., 21, f. 14, 3 de março de $1825 ;$ f. $88 ; 23$ de novembro de 1825.

(20). - Col. A. S. P., 20 f. 103,5 de outubro de 1821 .

(21). - Idem., 18, f. 67, 15 de fevereiro de 1817. 
seguinte escreve, em abril, a um senhor de Campinas para assegurarse da próxima safra (22). Não raro, entretanto, por uma série de razões, ainda procura comprar açúcar às vésperas ou no decurso da colheita. A 30 de junho de 1818, escrevia para Pôrto Feliz, a fim de informar-se sôbre se conseguiria mais açúcar, pois soubera que um senhor de engenho tinha sua "safra em ser" (23). Em julho procura ainda uma segunda safra (24). Logo em seguida, pretende viajar para Campinas, a fim de comprar mais (25). Ao mesmo tempo pede a um intermediário que the consiga mais quatro ou cinco safras de açúcar em Campinas (26), e, em agôsto, recebe a oferta de quatro safras daquela Vila (27). Enquanto espera para fechar o negócio em Campinas, comunica que tinha conseguido comprar algumas safras em Itú e Pôrto Feliz (28). Em setembro, procurava ainda conseguir mais açúcar. Isso tudo em 1818, ano em que o comércio de açúcar mais se avolumou (29).

As compras, depois de iniciada a safra, dependiam principalmente do volume das vendas do ano anterior e do preço que conseguisse o açúcar paulista no Rio de Janeiro. Não raro, existiam sobras do ano anterior em poder do comerciante que dificilmente podiam vender-se. Em 1819, escrevia Prado a seu correspondente no Rio de Janeiro - Manuel Moreira Lírio - para saber "a porção q mais ou menos existia em ser pa assim saber se devia continuar a fazer compras da nova safra, visto q até agora só tenho comprado $4000 \mathrm{a}$. receozo de maior empate nesse"... (30). Assim, quando as vendas tivessem sido boas no ano anterior, o comerciante se interessava em obter bastante açúcar antes da safra seguinte. Por outro lado, só nesse caso ou quando o preço era favorável, ainda comprava depois do início da safra .

Prado comprava geralmente as safras dos engenhos de duas maneiras: entrava em contato direto com o proprietário ou, procurava-o através de um intermediário na Vila inde se situasse o engenho. Esse intermediário podia ser um parente, um amigo, ou mais frequientemente, uma pessoa com quem já mantinha relações comerciais de outra natureza. Muitas vêzes, tratava-se, por exemplo, de seu cobrador ou administrador das rendas públicas, cujo contrato tinha arrematado. Isso explica a disponibilidade de capitais nas áreas ca-

\footnotetext{
(22). - Idem., 18, f. 97 vs., 19 de abril de 1818.

(23). - Idem., 18, f. 124,30 de junho de 1818 .

(24). - Idem., 18, f. 134, vs., 27 de julho de 1818.

(25). - Idem., 18, f. 138,13 de agôsto de 1818 .

(26) . - Idem., 18, 1. 133, 23 de julho de 1818.

(27). - Idem., 18, f. 140,19 de agôsto de 1818.

(28) . - Idem., 18, f. 140,19 đe àgôsto de 1818.

(29). - Idem., 18, f. 74 vs., 9 de setembro de 1817 .

(30) . - Idem., 19, f. 129 vs., 1 de setembro de 1819.
} 
navieiras (e também fora delas), que podiam ser aplicados na compra do produto nos engenhos. Esses capitais, entretanto, muitas vêzes já deviam ter chegado as mãos de Antônio da Silva Prado, que os remetia novamente às Vilas açucareiras. Geralmente, dava aos encarregados da compra de safras, amplos poderes, naturalmente porque se tratava de pessoas de sua inteira confiança.. Em janeiro de 1818, escrevia a Elias Antônio Pacheco, em Itú, encarregado de comparar a safra de Joaquim de Almeida "pelo preso q'Vmce com elle tractar certo na ma satisfação em qto obrar" (31). Encarregava José Custódio de Oliveira, de Pôrto Feliz, de ver se determinado senhor de engenho queria vender a safra pelo preço que os demais cobravam e frisava que tudo o quanto o intermediário "tratar a este respeito pr esta me obrigo a cumprir certo em q'em tpo algum darei motivo a q'vmce se arrependa em ser agente de tal negocio" (32). $\mathrm{O}$ intermediário comprava sempre mais de uma safra e, muitas vêzes, tinha açúcar de sua própria produção (33).

Ignácio Antônio de Correia, de Campinas, foi encarregado, em 1818 , da compra de quatro ou cinco safras que tivessem mais ou menos 500 ou 600 arrôbas (34). Como se tratava de um negócio importante, Prado pedia a um senhor de engenho "certificar aquelles q' com elle tratarem q' eu pr tudo respondo, sem haver duvida, pois mtos vivem escandalizados, pr isso temem tratar negócios de safras pelos preços correntes, e eu pelo contrário, q' hé hũ negocio q' não admite duvida algũa, e VS como ja tratou comigo este negocio e estamos certos, em continuar este prese. anno bem poderia enformar o bem, ou o mal q' se deu crmmigo em tal negocio aos Srs q' quizerem tratar com o dọ Corrẹ" (35). Logo em seguida, Antônio da Silva Prado recebeu de um parente a oferta de quatro safras e encarregava, outra vez, seu intermediário, Ignácio Antônio Correia, para "saber se fica tratado", o tal negócio (36). Como êste deu resultado, pede ao intermediário para não continuar mais na "diligencia de comprar me assucar" (37). Nessa ocasião, comprou cerca de 11000 arrôbas em Campinas, vindo "dos Engos do Ten. Corel Ar ra $^{\mathrm{a}}$, do Pe $\mathrm{Ar}^{\mathrm{a}}$, do Capm Seqra dos dois do Sarg mor Foriano q' são 2 pontes e ponte alta" (38). O primeiro era o que devia dar as informações sôbre os negócios e o segundo é o parente que lhe oferecera as quatro

\footnotetext{
(31). - Idem., 18, f. 91,6 de janeiro de 1818.

(32). - Idem., 18, 30 de junho de 1818.

(33) . - Idem., 18, f. 188,18 de novembro de 1818.

(34) . - Idem., 18, f. 133, 23 de julho de 1818 .

(35) . - Ibidem.

(36) . - Idem., 18, f. 140, 19 de agôsto de 1818 .

(37). - Idem., 18, f. 142, 29 de agôsto de 1818 .

(38) . - Iaem., 18, f. 147, 16 de setembro de 1818 .
} 
safras. Nesse caso a incumbência do intermediário não foi procurar as safras, mas, ver se o negócio seria fechado.

Algumas vêzes os senhores de engenho muito escrupulosos não queriam receber o dinheiro sem que antes Antônio da Silva Prado tivesse obtido do intermediário a confirmação da quantidade de açúcar fornecida. Foi o caso, por exemplo, de Frei Joaquim de Campinas, que não queria receber, sem que antes Joaquim Aranha de Camargo, senhor de engenho, mas que tinha funcionado como intermediário, desse informação sôbre o número de arrôbas fornecidas (39).

$O$ intermediário, nas vilas, há de intervir, não raro, na questão de preços. Como, no momento, os negócios de açúcar, iam mal, Antônio da Silva Prado escreve a Luís Gonzaga de Santa Gertrudes, em Itú, para que, se os senhores de engenho quizerem mais de 1.280 réis por arrôba de açúcar branco, dizer-lhes "aquelles de qm vmce comprou, e deo $600 \mathrm{rs}$ pr conta $q$ vendão a outrem, e tornem-lhe a dar a d ${ }^{a^{\prime}} \mathrm{qt}^{\mathrm{a}}$ sendo isto em termos q' não fiquem mal satisfeitos com vmce, e a tanto quererem aceite sem repugnancia" (40). Vê-se que deve ter comprado não pequena quantidade de açúcar em Itú. Só queria ficar com uma safra, pois parte dessa já tinha ido para Santos. Era o ano em que tinha comprado muito açúcar e em que os seus negócios não iam correndo bem, devido à queda do preço do produto paulista no Rio de Janeiro.

Mais tarde, em 1821, Prado procura safras de açúcar não só para sí, mas principalmente, para seu correspondente, em Santos, o qual estava interessado no comércio do açúcar por conta própria, como veremos adiante (41).

Naturalmente, não encontramos na correspondência tôdas as informações sôbre suas compras de safras de açúcar. E' provável que tenha tratado pessoalmente de muitas delas com os intermediários ou com os próprios senhores de engenho quando vinham a São Paulo ou quando êle próprio ia às áreas açucareiras. São Paulo era centro de convergência da vida econômica, política e administrativa da Capitania, de maneira que os senhores de engenhos e os intermediários deviam aparecer na Capital com certa frequiência, sendo assim possível o trato direto. O próprio Antônio da Silva Prado, por sua vêz, ia ocasionalmente ao interior e entrava em contato com os senhores (42). Pela correspondência pode-se ver que o intermediário era importante, aparecendo, certamente, como figura significativa nas vilas açucareiras. Não sabemos, entretanto, de que maneira era grati-

(39) . - Idem., 18, f. 86 vs., 8 de fevereiro de 1818.

(40). - Idem., 18, f. 183 vs., 12 de novembro de 1818.

(41) - - Idem., 20, f. 1,17 de janeiro de 1821 ; f. 86 vs., 29 de agôsto đe 1821 .

(42). - Idem., 18, f. 138, 13 de agôsto de 1818: "pertendo hir. para hír a festa de Campinas aver se consigo comprar alguas safras". 
ficado pelo seu trabalho. Prado geralmente negociava sempre com os mesmos proprietários. Quando em dado ano acerta as contas do anterior, já fala na sâfra seguinte, assim aconteceu por exemplo com relação a Joaquim Aranha de Camargo, de Campinas, em 1818... "já lhe falo na sua safra pr q eu gosto de negociar sempre com qm negoci hũa ves" (43). Parece que continuou a comprar açúcar do mesmo senhor de engenho até 1821, quando destratou a safra, devido à má qualidade do açúcar (44). De outro senhor de engenho de Campinas, Antônio da Silva Prado quer comprar outra safra em 1819: "Hé minha vonte ficar com sua nova safra e pr isso lhe certifico ficar com ella pela mma forma $q$ tenho ficado com as antecedentes" (45). Ao que parece, raramente acontecia o próprio senhor de engenho levar sua produção para Santos (46). Em geral, vendia o açúcar no próprio engenho a algum comerciante que se encarregava de o mandar buscar e transportar ao lugar de embarque.

Qual seria a quantidade de açúcar adquirida pelo futuro Barão de Iguape? A sua correspondêricia, apesar de muitas minúcias, não deixa claro quanto êle comprava em cada safra dos engenhos. Muitas vêzes, perce-se que as cifras relativas ao produto vindo dos engenhos, não correspondem inteiramente às suas remessas para Santos e Rio de Janeiro. Assim não se pode verificar, através das cartas, a quantidade do açúcar comprado na safra de 1817-1818. Sabe-se que no ano seguinte, 1818-1819, aumentou muito o volume das compras do produto por Antônio da Silva Prado. Em outubro de 1818, afirma êle em carta para Campinas que tinha perto de 20.000 arrôbas de açúcar compradas (47). Mais tarde, quando a safra estava terminando, refere-se a 18.000 arrôbas (48). A maior parte procedia de Campinas; mais ou menos onze mil arrôbas, oriundas de poucas fazendas (49).

Como Prado encontrara dificuldade em vender todo êsse açúcar c os preços fôssem pouco vantajosos, no ano seguinte - 1819-1820 adquiriu pequena quantidade. Em setembro de 1819 , em carta ao seu correspondente no Rio de Janeiro, onde pede informações sôbre o volume de açícar de sua conta ainda por vender, afirma que com-

\footnotetext{
(43) . - Idem., 18, f, 97 vs., $-98,10$ de abril de 1818 .

(44) . - Idem., 20, f. 131, 19 de dezembro de 1821.

(45). - Idem., 19, f. 96 vs., 23 de maio de 1819.

(46) - - No entanto o tio de Antônio da Silva Prado, Manuel Rodrigues Jordão, exportava êle próprio o açúcar produzido nos seus engenhos para santos e para o Rio de Janeiro. Depois em 1821. "o tio Jordáo vendera este anno o assucar que tinha nos Engos., e diz q assim pertende fazer todos os annos' (20, f. 102 vs.).

(47). - Idem, 18, f. 168,22 de outubro de 1818 .

(48) . - Idem., 19, f. 77 vs., 11 de abril de 1819 .

(49) . - Idem., 18, \&. 145, 16 de abril de 1818.
} 
prara sòmente 4.000 arrôbas "receoso de maior empate nesse" (50) Não ficou nas 4.000 arrôbàs. Em outubro escreve ao correspondente em Santos - Cipriano da Silva Proost: "só conto com 6.000 a. pr que tenho ingeitado comprar pelo preço que correr, visto qu não me deei bem com este negocio" (51). Parece que nessa safra não comprou mais açúcar, pois em março de 1820 , afirmava que ao todo não chegava a 6.000 arrôbas (52). Explicava que tinha "obviado $\mathrm{p}^{\mathrm{a}}$ o Rio a remessa afim de não suportar gres delongas como acontece me.com a safra passada, e o pouco he mais facil ter estracção qdo acresce ter havido alguma alteração de preços em Itú e Campinas e essa a maior razão de ter desprezado alguas safras" (53).

Além dos negócios de açúcar não irem bem no Rio de Janeiro, o preço do produto no engenho tinha aumentado. A tudo isso se junta ainda o fato de as safras terem sido muito pequenas (54). Vêse que o volume de açúcar comprado por Antônio da Silva Prado diminuira muito. O comerciante ficara muito assustado no ano anterior com a possibilidade de grandes prejuízos. Isso o fêz desistir de empatar grandes somas nesse negócio. Ainda mais que o açúcar pàılista tinha péssima reputação no Rio de Janeiro, não podendo competir com o de Campos.

São Paulo ainda estava tentando conquistar seu lugar no comércio de açúcar no País. Antônio da Silva Prado escrevia: "O estado actual do comercio nesta hé desgraçado pr qe tendo eu feito o ano passado, e este o empate de 40:000\$000 em assucar me acho com hum empate extraordinro e, com mais de trez mil a. em ser".... (55). I oi nesse ano que os comerciantes de Santos começaram a vender mais açúcar para Montevidéu e Buenos Aires. Um bergantim inglês com dificuldade conseguia algum açúcar no mesmo pôrto (56), pois tudo tinha sido vendido para o Sul.

No ano seguinte, Antônio da Silva Prado também comprou pouco açúcar, e em sua correspondência há escassas referências. Parece, entretanto, que estava mais animado, pois, em agôsto de 1820, escrevia ao correspondente em Santoš... "e agora damos princípio a nova vida $\mathrm{p}^{\mathrm{a}}$ o que comprei mais hĩ dia destes hua safra de bom assucar e desejarei que venha vindo logo $\mathrm{p}^{\mathrm{a}}$ a remessa que pertendo $\mathrm{p}^{\mathrm{a}} \mathrm{o}$ Rio Grande" (57). As compras, porém, não devem ter ultrapassado de muito 5.000 arrôbas, pois, em outubro de 1820 , oferecia "as

\footnotetext{
(50). - Idem., 19, f. 129 vs., I de setembro de 1819.

(51). - Idem., 19, f. 147 vs., 19 de outubro de 1820 .

(52). - Idem., 19, f. 211 vs., 23 de março de 1820.

(53). - Idem., 19, f. 179,12 de janeiro de 1820.

(54) . - Idem., 19, f. 204, 12 de março de 1820.

(55). - I Iem., 19, f. 227, 8 de maio de 1820.

(56) . - Idem., 19, f. 204, 12 de março de 1820 .

(57). - Iãem., 19, f. 270,16 de agôsto de 1820 .
} 
5.000 a. de assucar q tenho comprado nesta prez te safra" ao correspondente, que queria comprar todo seu açúcar, dando-lhe $12 \%$ a mais do que o preço pago nos engenhos (58). As safras de 18201821 também não foram muito abundantes e Antônio da Silva Prado comenta, em novembro de 1820 , que "não há quaze asucar e o mmo sobro do Ara esperava $5 \$ 000$ a.s e penço dará graças a Deus se fizer $2 \$ 000 "(59)$.

Finalmente, em 1821-1822, Prado abandonou quase completamente êsse comércio. Deve ter comprado pouco, pois, em setembro de 1821, comunica a seu correspondente em Santos: "O meu assucar hé mto pouco este anno pois thé o prezte só tenho a safra do Ara, e terei mais algm me derem em pagamto, pois estou cansado em lutar com este negócio há 5 annos, e duvido q esteja salvo de prejuizos e pr isso tenho recorrido a outros meios" (60).

Sendo grande comerciante, preferia naturalmente comprar safras volumosas. Em julho de 1818 , pede a seu intermediário, em Campinas, que the procure quatro ou cinco safras" que ande mais ou menos pr 5 a 6000 a." (61). Comprou ali, naquele ano, 11000 arrôbas "que são dos Engos do Ten. Corel Ar"a, do Pe Ara, do Capm Serqra e dos dois do Sargmor Floriano q' são 2 pontes, e ponte alta" (62). Trata-se, portanto, de açúcar comprado em cinco engenhos. As safras do sargento-mor Floriano eram estimadas em 6.000 arrôbas e a do padre Aranha em 1.200 (63).

As șafras excederam, às estimativas prévias. Esse foi um ano excepcional para o comércio de açúcar de Antônio da Silva Prado. Os dados mostram a capacidade econômica dêsse comerciante, que podia comprar safras de tamanhos engenhos. Tratava-se, certamente, dos maiores estabelecimentos açucareiros paulistas. As referências ao volume das safras compradas, entretanto, não são muito frequientes. Parece que as outras aquisições de Antônio da Silva Prado, mesmo em anos posteriores, são menos volumosas. Em 1820-1821, a safra de Francisco Egídio de Souza Aranha, que adquiriu, foi de 1.219

(58). - Idem., 19, f. 298, 11 de outubro de 1820 .

(59). - Idem., 19, f. 314 vs., 17 de novembro de 1820 .

(60). - Idem., 20, f. 91,5 de setembro de 1821 .

(61). - Idem., 18, f. 133, 23 de julho de 1818 .

(62) . - Idem., 18, f. 147, 16 de setembro de 1818 .

(63). - Idem., 18, 1. 141, 19 de agôsto de 1818. Por ocasião do acerto de contas, verificou-se que a safra do padre Aranha era de 1.926 arrôbas e 20 libras (662 arrôbas e 24 libras do branco, 704 do branco tnfertor, 419 arrôbas e 30 libras de redondo e 139 arrôbas e 30 libras do mascavo) (Idem., 19, f. 141, 24 de setembro de 1819). A safra do engenho das Duas Pontes foi de 5.017 arrôbas (3.340 arróbas do branco, 1.364 do redondo e 313 do mascavo) (Idem., 19, f. 135, 9 de setembro de 1819). A safra do engenho da Ponte Alta fol de 2.086 arrôbas (1.400 do branco, 464 do redondo e 200 do mascavo) (Idem., 19, f. 109, 30 de junho de 1819). 
arrôbas, sendo 218 de branco, 479 de redondo "porem de tão má qualidade q só merece o titulo de mascavo", e 522 de mascavo (64). Nas cartas há muitas referências a quantidades bem menores que vinham de engenhos pequenos ou de outros que não vendiam tôda produção a um só comerciante. Assim, por exemplo, escreve em setembro de 1818 a um senhor de engenho de Itú que não tinha recebido ainda as dezenove arrôbas compradas (65). Em outra ocasião, pede que the sejam enviadas as 30 ou 32 arrôbas de açúcar branco que comprara (66). Ou avisa que não tinha dúvida em receber 500 arrôbas (67). Como as cartas não são muito explícitas, quando se referem a quantidades, fica-se, muitas vêzes, sem saber se o açúcar recebido é tôda a safra ou apenas a parte remetida a Santos.

O preço pago pelo comerciante no engenho dependia naturalmente da conjuntura econômica. Atuavam sôbre os preços nos engenhos o montante da safra correspondente e o preço que o produto paulista conseguia, tanto no Rio de Janeiro como em Santos. Naquela época, o açúcar paulista dependia principalmente do mercado do Rio, de maneira que as flutuações de preço naquela cidade repercutiam diretamente sôbre os dos engenhos.

Pela correspondência de Antônio da Silva Prado, pode-se ver quanto recebia o proprietário pelo seu produto. Geralmente, como vimos, êsse comerciante comprava o açúcar no engenho, antes do início da safra, deixando aberta a questão dos preços para pagar "preço geral q' correr nessa Villa aquelas safras de igual conceito" (68). Ou, então, comprava a safra "pelo preço q' os mais senrs Engenheiros venderem" (69). Em alguns casos, apesar de deixar aberta a questão dos preços, dava um sinal correspondente a uma parte do total quando fechava o negócio (70). Em 1818, mostra, numa carta a Joaquim Aranha de Camargo, que lhe tinha arranjado algumas safras, algumas modalidades de pagamento: "estão prontos 2:000\$ rs q qr pr ter de dar ao do major Floriano e o q' tiver de dar aos sobredos major hirei dando conforme o recebimento do assucar e tudo que pertencer ao

(64) . - Idem., 20, f. 15 vs., 9 de março de 1821. No ano anterior (1819-1820) a safra fôra ligetramente malor: 1.326 arrôbas, sendo 610 arrôbas e 16 libras do branco, 405 arrôbas e 16 libras do redondo e 312 do mascavo (19. f. 213,28 de março de 1820).

(65). - Idem., 18, f. 146 vs., 15 de setembro de 1818.

(66). - Idem., 19, f. 90 vs., 5 de maio de 1819.

(67). - Idem., 19, f. 74 vs., 9 de setembro de 1819.

(68). - Idem., 18, f. 74 vs., 9 de setembro de 1817.

(69). - Idem., 18, f. 124, 30 de junho de 1818.

(70). - Idem., 19, f. 289, 22 de setembro de 1820. Depols de acertada a compra da safra escreve: "Tenho querido mancar o 1:000\$ rs por conta da safra conforme o nosso combinado tracto". Em outra ocasiăo, escreve ao mesmo senhor de engenho $(19, f, 276$ vs., 30 de agôsto de 1820), que quer a safra, mas náo podia pagar como lhe fôra pedido, por falta de moedas de ouro na praça. 
Sr. José Franco Aranha darei ou nesta Cide ou no Rio de Janro desta data a hum anno" (71).

As condições de pagamento, portanto, podiam ser as mais variadas. Podia pagar adiantado, pagar quando recebia o açúcar e pagar, inclusive, dentro do prazo de um ano. Parece, que se tratando de grandes safras, sempre dava um sinal quando fechava o negócio. Pedia a seu intermediário, em Campinas, que the devia comprar grandes safras, que o avisasse para poder remeter o dinheiro necessário para o sinal (72). A outro intermediário, de Itú, que devia fechar um negócio, escrevia que "o dro necessario $p^{a}$ tal compra ou remeterei aqui com determinação sua e certifico a prontidão qto as condisoens" (73). Ȧs vêzes, remetia antecipadamente o dinheiro do sinal. Assim, enviava a um intermediário de Pôrto Feliz 500\$000, "para ver se consegue algua safra de assucar" (74).

Apesar de não se fixar o preço por ocasião da safra, parece que nunca surgiam dúvidas entre o comerciante e os proprietários. ' $E^{\prime}$ pelo menos o que se pode deduzir de sua correspondência, pois não se encontra aí nenhuma referência a qualquer problema sôbre os preços na hora do acêrto das contas. Escrevia a respeito disso a um senhor de engenho, declarando que devia auxiliar o intermediário na compra de safras em Campinas: "muitos vivem escandalizados, e pr isso temem tratar negocios de safras pelos preços correntes, e eu pelo contrario, q' hé hũ negocio que não admite duvida alguã", como já vimos. A outro intermediário escreve que se obrigava a cumprir tudo que êste tratasse (75). Isso não queria dizer, naturalmente que pagasse sempre o preço corrente, quando o produto fôsse de má qualidade. Comprando o açúcar em época de safra, já fechava o negócio com o preço combinado.

Os preços, ao que se pode depreender das cartas de Prado variavam bastante. Na safra de 1817-1818, a cotação em Campinas fôra de 1.280 réis a arrôba do branco, 640 a do mascavo, variando a do redondo (76). Na mesma safra, pagou pelo açúcar branco, de um engenho de Itú, 1.900 réis (77). Não sabemos a que atribuir essa diferença. Talvez se tratasse de produto excepcionalmente bom, pois as diferenças determinavam-se pela qualidade. Em fevereiro de 1819 , por exemplo, pede a seu correspondente, em Santos, que cuidas-

\footnotetext{
(71) . - Idem., 18, f. 140,19 de agôsto de 1818.

(72) . - Idem., 18, f. 140,19 de agôsto de 1818 .

(73) . - Idem., 18, f. 81,6 de janeiro de 1818.

(74). - Idem., 18, f. 134, 27 de julho de 1818 .

(75) . - Idem., 18, f. 124,23 de julho de 1818 .

(76) . - Idem., 18, f. 97 vs. $-98,10$ de abril de 1818 .

(77). - Idem., 18, f. 146 vs., 15 de setembro de 1818.
} 
se bem de determinzdo açúcar, pois era de "mta boa qualide e custou me carissimo" (78).

$\mathrm{Na}$ safra seguinte (1818-1819), alguns senhores de engenho de Itú queriam 1.360 réis por arrôba de açúcar branco, $1: 000$ réis do redondo e 640 pelo mascavo. Apelando entretanto, para a situação do mercado carioca, onde o açúcar paulista não conseguia nem 2.000 réis a arrôba, devido à abundância do açúcar de Campos, escrevia Prado que não queria pagar a importância pedida, pois "comprando por tal preço de 1.360 o branco hé ter vontade de perder" (79). Na mesma ocasião, pede a seu intermediário de Itú, que, se os senhores de engenho exigissem mais de 1.280, devolvesse a soma dada como sinal. Nesta safra, o comerciante pagou em Campinas a 1.280 réis a arrôba de açúcar branco, 960 réis a do redondo e 640 réis a do mascavo, como no ano anterior (80). O açúcar branco inferior chegou a custar 1.180 a arrôba, (81).

$\mathrm{Na}$ safra de 1819-1820, oferece-se o comerciante para comprar açúcar alvo por 960 réis em Campinas (82). Nesse ano, faz-se sentir uma queda nos preçços do produto paulista. Em dezembro de 1819, comunicava que o preço era de 900,600 e 400 réis, a arrôba (83). A dificuldade de vender açúcar paulista no Rio de Janeiro deve ter sido sentida não sòmente por Antônio da Silva Prado. As vendas ali eram demoradas, pois o produto de São Paulo, de maneira nenhuma podia concorrer com o de Campos. No fim da safra parece que houve ligeira modificação dos preços nos engenhos e "esta a maior razão de ter desprezado alguas safras" (84). Comprou açúcar em Itú, a $1.050,700$ e 400 réis a arrôba (85).

Como já se interessasse menos, então, no comércio do açúcar, tornam-se mais raras as referências aos preços. Parece que, na safra de 1820-1821, houve aumento nos preços do açúcar nos engenhos. Em novembro de 1820 , os proprietários de Itú queriam 1.280 réis por arrôba, o que, segundo Antônio da Silva Prado, era um absurdo (86). Em março de 1821, afirmava êste que procuraria açúcar branco "pr mto menos do preço de $2 \$ 400$ q na verde hera mto caro" (87). A escassez do produto causou a alta do preço. Como já vimos,

\footnotetext{
(78)., - Idem., 19, f. 55 vs. - 56, 24 de fevereiro de 1819.

(79) . - Idem., 18, f. 183 e 183 vs., 12 de novembro de 1818 .

(80). - Idem., 19, 1. 100 vs., 30 de junho de 1819; 1. 127-128, 31 de agôsto de 1819; 1 . 141, 24 de setembro de 1819. Trata-se de acertos de contas.

(81). - Idem., 19, f. 141,24 de setembro de 1819 .

(82). - Idem., 19, f. 140 vs., 24 de setembro de 1819 .

(83). - Idem., 19, f. 164, 7 de dezembro de 1819 .

(84). - Idem., 19, f. 179,12 de Janeiro de 1820 .

(85). - Idem., 19, f. 195 vs., 15 de fevereiro de 1820.

(86) . - Idem., 19, f. 314 vs., 17 de novembro de 1820 .

(87). - Idem., 20, f. 15 vs., 7 de março de 1821.
} 
o próprio Antônio da Silva Prado escrevia a seu correspondente, em Santos, que não havia quase açúcar e que um senhor de engenho que esperava produzir 3000 arrôbas "dará graças a Ds se fizer $2 \$ 000 "(88)$.

A qualidade do produto influia de maneira decisiva no preço. Quando ainda não tinha muita prática do comércio do açúcar, Prado pediu a três outros comerciantes de São Paulo conselhos sôbre como agir em relação ao problema da qualidade. Escrevia em 1819 "Como vmce tem grande pratica no negocio do assucar, e eu pouca, vou pr isso rogar-lhe queira dizer-me se quando dos Engenhos the remeter assucar branco q' pelas guias de Stos vem com nota de branco inferior, ql he o rebate q costuma fazer em arroba"... (89). Não conhecemos a resposta dada. Na safra de 1818-1819, abateu 100 réis no valor do açúcar branco de má qualidade, de maneira que pagou 1.180 réis. Afirmava categòricamente: "A pratica entre Negociantes e Snr de Engenho hé sempre rebater $100 \mathrm{rs} \mathrm{em} \mathrm{a.} \mathrm{de} \mathrm{assucar} \mathrm{qdo} \mathrm{hé}$ inferior" (90). Em outra ocasião, afirmava que o açúcar branco não passava de um bom redondo e algumas pessoas consultadas recomendaram um abatimento de 200 réis por arrôba (91) .

Antônio da Silva Prado teve muitos problemas com o açúcar que recebia dos engenhos. Ou vinha açúcar "q diz ser mascavo, e não hé, e mais se assemelha a terra", ou desconfiava da qualidade do produto e queixa-se "pois eu quiz assucar de Itú pr me dizerem ser melhor do q de Campinas, porem não tem acontecido assim, com o q vm" me tem mandado, pois alem de ser todo redondo, e mascavo hé todo de infame qualidade" (92). Em outra ocasião, queixava-se de um senhor de engenho e pede a êste que não lhe mande mais açúcar, pois, além de só mandar redondo e mascavo, "hé ademais inferior qualidade possivel, de maneira q' não serve pr preço algũ”... "ou que mande assucar bom ou nenhũ" (93). Não é rara aliás a devolução de açúcar de má qualidade. Escreve a Joaquim Aranha de Camargo, de Campinas, em 1821, que o produto comprado por seu intermédio era, além de muito ruim, muito úmido e que, por isso, não queria ficar com êle. O senhor de engenho poderia pegá-lo em Santos ou vendêlo alí (94). O açúcar dêsse engenho devia ser mesmo muito ruim,

\footnotetext{
(88). - Idem., 19, f. 314 vs., 17 de novembro de 1820.

(89). - Idem., 19, f. 149, 26 de outubro de 1819. A mesma carta fol dirigida a três comerciantes.

(90) . - Idem., 19, f. 127 vs. - 128, 31 de agôsto de 1819 .

(91) . - Idem., 19, f. 102, 12 de junho de 1819 .

(92). - Idem., 19, f. 88,4 de maio de 1819 .

(93). - Idem., 19, f. 90,5 de maio de 1819 .

(94). - Idem., 20, f. 127,26 de novembro de 1821 e f. 129,29 de novembro de 1821 .
} 
pois Antônio da Silva Prado acabou destratando a compra da safra (95) .

Às vêzes, Prado ficava assustado com os comentários a respeito de açúcar comprado por êle: "que o peor assucar q tinha visto, era o

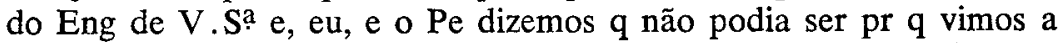
amostra do branco, e era superior pr isso veja como hé isto pois sempre foi, e he da ma intensão não prejudicar a pessoa algũa, nem tão pouco ser prejudicado"... (96). Não só o branco, mas também o redondo, podia ser de qualidade inferior. Francisco Egídio de Souza Aranha, de Campinas, vendera-lhe, além de açúcar branco e mascavo, também redondo "porem de tão má qualide q so merece o titulo de mascavo" (97). Em certa ocasião, refere-se a amostras que recebeu de Santos: "além do branco ser inferior como o mais, hé o redondo masco, e o mascavo não sei o q' hé"... (98).

Transcrevemos aqui um trecho de uma carta a Francisco de Aranha Camargo, de agôsto de 1819, na qual, além do acêrto de contas, há um parágrafo que se refere a qualidade do açúcar e suas implicações no comércio e nas relações entre comerciante e senhor de engenho: "V.S. bem sabe que não fiz negco algum com o Srgto $\mathrm{mr}$ Floriano e não estou sujeito a sacrificar-me a vonte delle, e a V.S. he a qm eu devia participar a inferior qualide do assucar como a fiz qdo V.S. nesta esteve não só do seu Engọ, como lhe disse q a safra da Ponte Alta tinha assucar de mto inferior qualide e tive do assucar retido mto tempo em Santos até q o Condutor entregasse os meus recibos ao do Sargto Mr e trouxece-me a esta os q passou a elle, como $\mathrm{fez}$ os qs tenho em meo poder, e pr isso nunca deve supor ignorancia e q lhe mostre pr onde me remetteo $\mathrm{d}^{\circ}$ assucar q pr ahi saberá a sua inferior qualide. A pratica entre os Negociante e Snrs de Engo hé sempre rebater $100 \mathrm{rs} \mathrm{em} \mathrm{a.} \mathrm{de} \mathrm{assucar} \mathrm{qdo} \mathrm{hé} \mathrm{inferior,} \mathrm{como} \mathrm{acon-}$ tece com as 598 de do Sargto mr; e mesmo V.S. viu eu assim praticar com o seu mano o $\mathrm{Sr}$ Tene Cel o qual esteve pr isso pois hé proprio todo homem de bem não querer enganar os outros, e a mim tem neste rebate todos os Snr de Eng. pr q nunca as safras podem ser de igual qualide no Eng do meo Thio Capm Eleutro e outros praticão qdo vão tirando das formas, vão pondo separado, branco bom, branco mais inferior e qdo remetem vai com a mma separação; parece-me tenho dito qto baste a este respto"... (99).

A outro senhor de engenho, cujo açúcar foi muito ruim, escrevia que este certamente não "esperava hua saffra tão má como esta e

(95) . - Idem., 20, f. 131, 19 de dezembro de 1821.

(96). - Idem., 19, f. 72,29 de março de 1819.

(97) - - Idem., 20, f. 15 vs., 9 de março de 1821.

(98) . - Idem., 19, f. 127 vs., 128, 31 de agôsto de 1819.

(99). - Idem., 19, f. 127 vs.. 30 de junho de 1819 . 
mmo pa mim da prejuizo pr constar só de assucar baixo e quaze nenhum branco, e estimarei q a futura seja melhor, não só pa proveito meo como pa interesse" dêle (100). O exemplo do comércio de Prado ilustra de maneira exata os problemas que existiam com relação à qualidade do açúcar paulista .

Como não via o açúcar que comprava, dependia, quanto às questões de pêso e qualidade, de seu correspondente em Santos - Cipriano da Silva Proost. Como êste, na guia passada aos condutores, não se referisse sempre à qualidade recebida, Antônio da Silva Prado saia prejudicado, pois só mais tarde ficava sabendo que êste ou aquêle senhor tinha remetido açúcar ruim. Pedia, então, ao correspondente: "Os assucares q receber e não achar suficientes declare nas guias $\mathbf{p}^{\mathrm{a}}$ eu me saber haver com os Srs de Engo" (101) . Logo depois, é mais incisivo: "Os assucares de $\mathrm{m} / \mathrm{c}$ q' não achar suficientes deve declarar nos recibos $q$ dá aos condutores, assim como deve nos mmos recibos declarar, e fazer me aviso particular, q' chegou mto molhado, vindo pr este modo eu a ser prejudicado nas quebras q' se sofre ao enxugar e q não aconteceria se declarasse no recibo, pr q nesse caso eu faria um desconto q' equilibra-se a quebra, como praticão todos" (102). Finalmente, como o açúcar continuava dando quebras no pêso, depois de beneficiado, dizia ao correspondente em Santos: "so vm" hé q segue hũa regra diferente de todos, e torno a dizer-lhe q' os recibos q' vm" não declarar chegou molhado, toda quebra conta pr sua conta, visto que este descuido hé seo" (103).

Parece que o correspondente em Santos passou a ter mais cuidado quando recebia o açúcar dos condutores, pois Antônio da Silva Prado não se refere mais ao problema. Agora, as reclamações vão partir de senhores de engenho e condutores, para os quais Cipriano da Silva Proost exagerava. Assim, por exemplo, um condutor reclama contra Proost "em bater na guia sofrivel o assucar redondo, qdo hé superior pr isso qdo não houver razão de queixa não hé justo q' venhão as guias com nota" (104). Parece que os condutores reclamavam bastante, pois sôbre êles recaia a culpa quando o produto chegava úmido. Antônio da Silva Prado escreve a seu correspondente em Santos: "A nova spiculação q vm" acha nas guias hé porq os Engenheiros e mmo os condutores dizem q o assucar vem enxuto; pr isso q tambem la deve chegar, pois elles não devem recebe-los molhados no Engo e eu tambem de algũ hei de cobrar o prejuizo q me resulta" (105).

\footnotetext{
(100). - Idem., 20, f. 15 vs., 9 de março de 1821 .

(101) . - Idem., 19, f. 2, 24 de novembro de 1818.

(102) . - Idem., 19, f. 7 vs. - 8, 1 de dezembro de 1818

(103). - Idem., 19, f. 11, 3 de dezembro de 1818.

(104). - Idem., 19, f. 101, 8 de junho de 1819.

(105). - Idem., 19, f. 109, 30 de junho de 1819 .
} 
Em outra ocasião, um senhor de engenho reclamou e o comerciante pede ao correspondente em Santos que lhe envie as amostras para verificar a qualidade, pois de outro açúcar Proost havia afirmado que não era bom, mas Antônio da Silva Prado mostrou-o em São Paulo e "dicerão-me que era mto bom assucar" (106). Havia portanto dois problemas a enfrentar: açúcar que já sai ruim do engenho e o que se estraga no percurso.

Parece que a qualidade do açúcar recebido dos engenhos também foi das causas do crescente desinterêsse de Antônio da Silva Prado pelo comércio dêsse produto. Em 1820, escrevia que certa quantidade de açúcar, enviada ao Rio de Janeiro, tinha sido comprada em Santos "pr não atuarar os Snr de Eng" q dão assucares mto inferiores" (107).

A compra de açúcar dos senhores de engenho não raro está ligada a outros negócios de Antônio da Silva Prado como, por exemplo, a aquisição de escravos. Assim, em 1818, recebeu diversas safras em Campinas para comprar escravos no Rio de Janeiro. A um senhor de engenho escreve que não tinha "duvida em esperar o anno vindouro o q' faltar qdo a sua safra não chegue ao valor dos dos escravos" (108). Francisco Egídio de Souza Aranha, que vendeu as safras de 1818-1819 e de 1819-1820, encomendou 20 escravos a serem buscados no Rio de Janeiro (109). Outro senhor de engenho, que também servira de intermediário na compra de safras de 1818 , encomendou escravos (110). Vê-se que o açúcar recebido era dado em pagamento de escravos que deveriam ser comprados no Rio de Janeiro. Tratava-se, ao que parece, de negociações esporádicas de pequeno número de escravos.

Grande comerciante que era Antônio da Silva Prado devia naturalmente ter elevado número de devedores. Assim, não raro, recebia açúcar como pagamento de dívidas. Salvador Bueno da Silveira, dono do engenho de Atibaia, oferece, por exemplo, 100 arrôbas de açúcar para saldar uma dívida, em parte já vencida, em parte ainda a vencer-se (111). Antônio da Silva Prado recusou-se a receber açúcar para o pagamento de uma dívida de outro senhor de engenho, por tratar-se de produto muito inferior. O próprio senhor de engenho

(106). - Idern., 19, f. 34, 20 de Janeiro de 1819 .

(107). - ldem., 19, f. 186 vs., 28 de janeiro de 1820.

(108). - Idem., 18, f. 148,7 de setembro de 1818.

(109). - Idem., 18, f. 168,22 de outubro de 1818.

(110) . - Idem., 19, f, 72,29 de março de 1819.

(111). - Idem., 19, f. 52 vs., 17 de fevereiro de $1819 ;$ f. 154 vs., 16 de novembro de 1819. 
resolveu então mandar o produto ao Rio de Janeiro e Antônio da Salva Prado recebeu a soma apurada (112). Em outra ocasião o comerciante mandou penhorar o açúcar para obter o pagamento de sua dívida (113). Des certa feita, pede a seu cobrador, em Pôrto Feliz, que cobre a dívida para outra pessoa e afirmava: "qdo seja necess receber assucar bom, pelo preço geral q' corre nessa não tenha duvida em aceitar" (114).

O açúcar tinha tanta importância em São Paulo, que todos o recebiam em pagamento de dívidas. Naturalmente, a queda dos preços podia servir de pretexto para o não pagamento de obrigações (115). Como arrematante de grande parte das rendas públicas, Prado não raro recebia açúcar ou aguardente em pagamento dêsses impostos. Seu cobrador do Subsídio Literário recebeu como pagamento açúcar e aguardente que mandou para o Rio de Janeiro. Ele e Manuel Moreira Lírio tinham arrêmatado êsse imposto (116). Uma boa safra de açúcar propiciava a rápida cobrança. Em 1821, escreveu a seu cobrador em Itú: "Penço q agora não será dificultozo fazer as cobranças do que me devem dos contratos, há muito assucar e he bom tempo, e mmo pr qro indireitar as contas do novo imposto dos annos de 1817, 1818,1819 " ... (117). Sendo negociante dé açúcar e arrematante da cobrança de rendas públicas, naturalmente deviam aparecer em seus negócios as implicações dêsses dois setores. Assim, um senhor de engenho, do "qual comprara a safra, era também seu cobrador e Antônio da Silva Prado lhe escrevia "pr isso pode servir-se dos dinros $\mathrm{q}$ de $\mathrm{m} / \mathrm{c}$ tem cobrado já" (118).

\section{$*$ \\ II). - O Transporte de Açúcar para Santos.}

O transporte até Santos constituía um dos principais fatôres do prejuízo do açúcar paulista com relação à qualidade. Como grande comerciante, Antônio da Silva Prado não pôde deixar de sentir os problemas decorrentes da condução do produto até o pôrto.

Além de estragar-se o açúcar no caminho para Santos, fato ao qual, entretanto há relativamente poucas referências na correspondência, havia ainda o problema da demora da condução. Os conduto-

(112). - Idem., 19, f. 149, 26 de outubro de 1819.

(113). - Idem., 19, f. 301 vs., 16 de outubro de 1820 .

(114). - Idem., 19, 1. 312 vs., 10 de outubro de 1820.

(115). - Idem., 19, f. 205, 14 de março de 1820 .

(116) . - Idem., 19, f. 45 vs., 10 de feverelro de 1819.

(117). - Idem., 20, f. 188 vs., 29 de agôsto de 1821 .

(118). - Idem., 19, f. 267,9 de agósto de 1820 . 
res ou faziam a viagem muito vagarosamente ou demoravam em buscar o produto nos engenhos. Uma ou outra vez, o comerciante não tinha pressa, pois "já se queixa o recebedor em Stos q esta com o armazem cheio e não pode dar vazão" (119).

Havia, também, o problema da estação chuvosa. Prado pede que lhe enviem o açúcar logo que estiver enxuto "inda q' seja em pequenas porções". .. "em razão de aproveitar o melhor tempo e chega a Santos melhor q' nas aguas" (120). Em outra ocasião escreve que o senhor de engenho "conclua a remessa de seo assucar com a bravide possivel, visto q neste tempo chega enchuto em Santos" (121). O negociante tinha interêsse em que o produto fôsse levado antes do comêço da estação chuvosa, para impedir os estragos durante a viagem.

Devido à premência dos negócios, muitas vêzes tinha pressa . São comuns os pedidos a intermediários, proprietários e condutores no sentido de fazerem o possível para remeter logo o açúcar para Santos. Escreve a um senhor de engenho que o remeta mesmo com condução cara "pois o q qro hé brevide pr q esta mto me convem" (122). Ao intermediário escrevia sôbre o mesmo açúcar: "Torno novamente a suplicar the o favor de encaminhar algs condutores $\mathrm{p}^{\mathrm{a}} \mathrm{o}$ Engenho de J Pera afim de conduzirem todo o assucar $q$ la tenho pois the o prezte apenas tem passado 300 e tantas arrobas e como tenho precisão q seja conduzido com brevidade"... não se importava em pagar frete mais caro (123).

De certa feita, precisava de açúcar em Santos para carregá-lo numa embarcação destinada a Bahia. Escrevia aí a seu intermediário: "Tenho muita precisão q' me mande com brevide possivel hũa condução de $200 \mathrm{a}$. de assucar para cima" (124). Isso, em setembro de 1818. Em meiados de outubro ainda não tinha chegado o açúcar desejado. Assim, tenta obter a quantidade necessária de seu tio, em Jundiaí: "Como fiz certo ao Cel Bento Thomaz em lhe dar no fim deste mez 200 a. de assucar em 50 sacos pa hir na Embarcação do mmo pa a Bahia, pr estes dez a 12 das e como até o preze não tem sido possivel passar nenhũ de ma conta, rogo a vmce mandar me do seu na tropa e q esteja em Stos pr estes 8 a 10 das afim de eu não ficar mal" (125). Nem assim conseguiu o produto, talvez por culpa

(119) . - Idem., 18, f. 188, 18 de novembro de 1818.

(120) . - Idem., 18, f. 141, 23 de agôsto de 818.

(121) . - Idem., 19, f. 312,10 de novembro de 1820 .

(122). - Idem., 19, f. 196, 19 de fevereiro de 1820.

(123). - Idem., idem.

(124). - Idem., 18, f. 151, 23 de setembro de 1818 .

(125). - Idem., 18, f. 165,16 de outubro de 1818 . 
dos condutores. Para satisfazer êsse compromisso, teve de pedir emprestado açúcar em Santos a outro tio.

Geralmente, era o intermediário quem arranjava os condutores. A um dêsses intermediários que devia comprar açúcar em Campinas, mas não o fêz porque Prado recebera oferta de um senhor de engenho, coube depois, encarregar-se de contratar os condutores: "Não prosseguira mais Vm" na diligencia de comprar me assucar, mas sim vou por esta encarrega-lhe de juntar condutores para a condução de dos assucares" ... "e com elles se entendera $\mathrm{p}^{\mathrm{a}}$ donde deve mandar os condutores, tratando Vmce as conduções e participando me Vm" the pagarei algua coisa pelo seo trabalho" (126). Promete aos intermediários que lhe arranjarem condutores que "tudo $\mathrm{qt}^{\mathrm{t}}$ tractar com os condutores prontame dezempenharei" (127). Nesse setor, o papel do intermediário é importante, não se conseguindo, entretanto, perceber como era remunerado para se encarregar do transporte.

Às vêzes, o próprio senhor de engenho procura os condutores. Antônio da Silva Prado pede a um senhor de engenho de Campinas que fale com o intermediário para "este mdar Condutor pegar em do assucar, ou vm" mmo diligenciara a Condução pa Santos" (128) .

Muitas vêzes, o comerciante já determinava de antemão a quem entregar o açúcar em Santos. Tratava-se, geralmente, de seu correspondente Cipriano da Silva Proost. Algumas vêzes, entretanto, pede ao condutor que, ao passar por São Paulo, o procure para lhe determinar a quem entregar o produto (129). A razão do condutor procurar o comerciante em São Paulo, porém, era o pagamento. "O assucar pode guiar em direitura a mim e esta $\mathrm{pr} q$ eu dou guia $\mathrm{p}^{\mathrm{a}}$ Santos pois assim me cumpre pr q costumo pagar as conduções nesta"... (130). Apesar dessa sua afirmação categórica, pode-se perceber pela correspondência que o pagamento também podia ser feito pelo correspondente em Santos, por conta do comerciante ou, o que era mais freqüente, na sua volta quando entregava a guia assinada em Santos. O pagamento do frete sempre corria por conta de Prado.

O preço da condução, como não podia deixar de ser, era de suma importância para o comércio. Encarecia o produto e diminuia a margem de lucro. Daí a importância que Antônio da Silva Prado dava ao assunto em tôda a sua correspondência. O frete, é lógico, variava, conforme a distância. O intermediário ou o fazendeiro ficava encarregado de tratar o preço até Santos. Escrevia em 1818, a seu intermediário em Campinas: "Visto a exposição que vmce me

(126). - Idem., 18, f. 142, 29 de agôsto de 1818 .

(127). - Idem., 18, f. 145 vs., 12 de setembro de 1818.

(128) . - Idem., 19, f. 52 vs., 17 de fevereiro de 1319

(129) . - Idem., 19, f. 52 vs., 17 de feverelro de 1819 .

(130) . - Idem., 19, f. 285,4 de setembro de 1820 . 
fez"... "em estarem os Caixões dos Engenheiros cheios, e haver mto assucar, e poucos condutores, hé de necessidade sujeitar-me ao preço q os mais dão aos Condutores, ou inda mais algũa coisa, e p' isso sobre este par não hé precizo mais consultar, e só lhe recomendo toda a sua.diligencia na remessa dos assucares, juntando como lhe parece, pois sabe que eu la não estou e por isso não posso calcular o preço q' os mais pagão, o q deve vmce fazer". O intermediário podia pagar de 10 a 20 réis a mais por arrôba segundo ordem de Antônio da Silva Prado (131). Nesse ano (1818), as conduções estavam caras e o comerciante pede a seu correspondente, no Rio de Janeiro, que the venda o açúcar a dinheiro, pois isso lhe convinha mais "em razão da carestia das conducções, com q' estou continuadamte a fazer despezas" (132).

Logo em seguida, pede a um senhor de engenho que não lhe mande mais açúcar "sem que a condução seja a 240 reis pr aroba, pois mais me convem ter demorado nos Engenhos do q' no Ro, principalmente com o exorbitante preço das conducções, e só sim se sugeitará à mandar àquelle q ao todo não tenha onde guardar" (133). A outro fazendeiro e intermediário em Campinas, também escreveu que não queria a condução mais cara que 240 réis a arrôba, pois "não devo procurar meios de prejudicar-me" (134). Não culpava, porém, o intermediário pelo alto preço dos fretes: "pr q' a ma ordem era q' acompanhasse aos outros; porem agora q' não me faz conta acompanhalos, torno novame certificar-lhe q' não quero me venha mais assucar a mais de 240, ou 280, só sim aquelle q' os Srs de Eng não tiverem aonde goardar, então nesse cazo vmce se sugeite ao exorbitante preço q' corre" (135).

$\mathrm{Na}$ safra anterior - 1817-1818 - já tinha havido aumento no preço da condução, pois, em fevereiro de 1818, escrevia: "continuarão aquerer de Campinas os Conductores 280 por arroba de assucar de aluguel e determinei não se dese amais de $240 \mathrm{pr}$ q' hé superfluo mdar pa o Rio pa se guardar" (136). Quando se deu a grande alta na condução de Campinas, os preços em Itú deviam ser semelhantes. Em novembro de 1818; a condução de Itú a Santos estava a 280 réis por arrôba (137), enquanto que, em setembro, ainda se falava em 190 réis (138). A alta dos preços da condução a Santos deve-se a grande quantidade de açúcar produzida naquele

(131). - Idem., 18, f. 164 vs., 16 de setembro de 1818 .

(132). - Idem., 18, f. 190 vs., 21 de novembro de 1818.

(133). - Idem., 18, f. 182 vs., 11 de novembro de 1818.

(134). - Ibidem.

(135). - Idem., 18, f. 188, 20 de novembro de 1818.

(136) . - Idem., 18, А. 88 vs., 17 de feverelro de 1818.

(137). - Idem., 18, f. 18312 de novembro de 1818.

(138) . - Idem., 18, 1. 146 vs., 15 de setembro de 1818. 
ano. Com o correr dos meses, na safra de 1818-1819, subiram ainda mais o fretes. Em março (1819), variavam de 320 a 340 réis por arrôba entre Campinas e Santos (139).

No comêço da safra seguinte, pede ao intermediário, em Campinas, que the arranje condução para buscar determinada produção comprada: "sujeitando-me a pagar os conds pelo preço q' for corre" (140). Em fevereiro (1920), o comerciante sujeita-se a pagar 400 réis por arrôba "como por ms algũa coisa, pois o q' qro he brevide" (141).

$\mathrm{Na}$ safra de 1820-1821, escrevia que as conduções estavam a 200 réis, sem precisar de onde, provàvelmente de Itú ou Campinas (142). De Pôrto Feliz a Santos ajustou a condução de açúcar a 280 réis por arrôba (143).

O preço do frete, como era natural, estava relacionado com a abundância do açúcar. Em safras pequenas diminuia muito, ao passo que em anos de abundância, subia exageradamente, cobrindo parte considerável do preço do produto. Em novembro de 1820, Antônio da Silva Prado arranjou dois condutores para buscar açúcar em Campinas, com duas tropas grandes que "são freguezes e não são rezingueiros". O comerciante ainda asseverava a seu correspondente em Santos, que lhe queria comprar todo o açúcar que "não tenha receio q a condução suba, pr q não ha quaze assucar" (144).

Pelas referências na sua correspondência, pode se ver a importância que tinha o preço da condução para o comércio de açúcar. Lamentável é que não se pode fazer o quadro completo dos fretes, por falta de elementos. Acreditamos que naqueles anos, devem ter girado em tôrno das cifras que citamos. Saint Hilaire, falando dos tropeiros de Campinas afirmava que o preço do transporte até Santos, em 1819 era de 340 a 400 réis por arrôba. Alude a preços ainda mais altos para o transporte entre Pôrto Feliz e Santos - uma pataca e meia ou seja 480 réis - justificando-o pela dificuldade na obtenção de milho (145) .

Qual a quantidade de açúcar que levaria cada tropa a Santos? $\mathrm{Na}$ correspondência de Antônio da Silva Prado temos alguns dados a respeito. Naturalmente, dependia do tamanho da tropa. Em novembro de 1818 , foram enviados 10 conduções de açúcar, com 2.304

\footnotetext{
(139). - Idem., 19, f. 72, 29 de março de 1819.

(140) . - Idem., 19, f. 140 vs., 24 de setembro de 1819.

(141). - Idem., 19, f. 196, 19 de fevereiro de 1820 .

(142). - Idem., 19, f. 317,23 de novembro de 1820 .

(143) . - Idem., 19, f. 312 vs., 10 de novembro de 1820.

(144). - Idem., 19, f. 314 vs., 17 de fevereiro de 1820.

(145) . - Saint Hllaire, Augusto de, Viagem a Provincia de são Paulo, Provincia Cisplatina e Missóes do Paraguai, p. 150 e 244.
} 
arrổbas e 23 libras (146). Cada condução teria levado assim, em média, cerca de 230 arrôbas de açúcar. Em outra ocasião, doze conduções levaram 1.926 arrôbas, o que daria aproximadamente 160 arrôbas por tropa (147), ao passo que certa vez treze tropas levaram 5.017 arrôbas, sendo a média de 386 arrôbas (148). Raras, aparentemente, as tropas que transportavam quantidades muito grandes. Há referências a conduções que transportaram 626,500 e 392 arrôbas (149) . Há, igualmente, notícia de pequena quantidade, 42, 19,30 ou 32 (150).

Antônio da Silva Prado, geralmente servia-se de vários condutores mas em setembro de 1818 , ano em que mais açúcar tinha comprado, pede a um condutor que "esta prezte safra a sua tropa só conduza assucar de $\mathrm{m}^{\mathrm{a}}$ conta"... "The ficarei obrigdo e a respto do preço dos fretes não terei duvida nenhua em pagar lhe pelo preço q' os mais levarem de Engos de iguais distancias" (151).

Além da questão de preços, há outros problemas com os tropeiros. Muitos eram descuidados e o açúcar perdia em quantidade $\epsilon$ qualidade. Na tropa de seu tio, Eleutério da Silva Prado, por exemplo, houve quebra de uma arrôba e meia no açúcar branco e de oito libras no redondo. O prejuízo, devendo ser pago pelo condutor ou pelo fazendeiro foi neste caso átribuido ao senhor de engenho, pois ficou provado que êste não agira corretamente (152). Em outra ocasião, houve quebra de dez arrôbas e dezoito libras, que o comerciante considerou extraordinário. Antônio da Silva Prado não sabe a quem atribuir a culpa e escreve a seu correspondente em Santos, que os condutores "me dizem vm" só peza hũ ou 2 sc e pr q ve q o pezo do Sargmor Floriano hé mto bom não procegue a pezar los e pr esta forma virei ahi a perder mtas a. de açúcar" (153).

O correspondente em Santos devia conferir o peso e marca-lo no recibo (guia) que dava ao condutor. Com relação ao pêso do açúcar comprado do Sargento Mor Floriano, o comerciante se queixa, em certa ocasião, diretamente ao intermediário: "he precizo ver o seu pezo q' esta diminuto pois em todos os assucares vindos do seo Eng. há quebra". Além disso, o produto chegava úmido em Santos, mas como o senhor de engenho tinha tido "a cautela de entregar a

\footnotetext{
(146). - Col. A. S. P., 18, 1. 184, 12 de novembro de 1818.

(147). - Idem., 19, f. 141, 24 de setembro de 1819.

(148) . - Idem., 19, f. 135,9 de setembro de 1819 .

(149). - Idem., 19, f. 96,23 de maio de 1819; 19 f. 281, 7 de setembro de 1820; 20, f. 113 vs., 24 de outubro de 1821 .

(150) . -Idem., 20, f. 206 vs., 10 de outubro de $1821 ; 18,1$, 146 vs., 15 de setembro de 1818 ; 19 , f. 90 vs., 5 de maio de 1819 .

(151). - Idem., 18, f. 147 vs, 16 de setembro de 1818 .

(152). - Idem., 18, f. 77 vs., 98,10 de abril de 1818 .

(153). - Idem., 19, f. 97 vs, 25 de malo de 1819.
} 
elles enxuto", os condutores ficavam responsáveis pela quebra de pêso indispensável para enxugar o produto (154). Os condutores portanto, recebiam, ou pelo menos deviam receber o açúcar sêco no engenho. Se chegasse úmido em Santos seria culpa dêles e teriam de pagar pelo prejuízo. No acêrto de contas entre o negociante e os condutores, havia portanto, também um desconto, caso o açúcar tivesse sido prejudicado, em quantidade ou em qualidade durante $\circ$ transporte.

No comércio do açúcar, o condutor ocupava lugar de destaque. Tinha por obrigação receber o artigo enxuto e com peso exato; se não chegasse a Santos como rezava a guia passada pelo senhor do engenho, era êle quem arcava com o prejuízo. Assim, por exemplo, Antônio da Silva Prado refere-se em carta a seu correspondente em Santos, que determinado condutor já lhe havia pago a quebra (155). A certo condutor não quiz pagar, pois o açúcar transportado era muito ruim e chegou todo molhado (156). Infere-se disso que o condutor devia funcionar como uma espécie de inspetor, fiscalizando a qualidade e quantidade de açúcar recebido, e não recebendo produto ruim. Naturalmente quando recebia açúcar em condições não satisfatórias, devia ter o cuidado de fazer constar isso na guia que recebia do senhor de engenho.

Para controlar o transporte dó açúcar para Santos, o condutor recebia do senhor de engenho uma guin em que constava a quantidade e qualidade do produto. $O$ açúcar devia ser entregue ao correspondente em Santos, juntamente com a guia. Essa assinada com a declaração de quantidade e qualidade era depois entregue a Antônio da Silva Prado em São Paulo. Às vêzes, principalmente quando êste começa a ocupar-se do comércio de açúcar, os condutores, passavam por São Paulo, onde recebiam nova guia. As guias, às vêzes causavam problemas. Em certa ocasião o condutor já tinha trazido recibo assinado pelo correspondente de Santos, sem que êste tivesse depois registrado a entrada do açúcar (157). Outro condutor havia passado por São Paulo na viagem de ida a Santos, e como não mais apareceu, o comerciante ficou preocupado e queria saber se o açúcar fôra entregue (158).

(Continua) .

(154). - Idem., 19, f. 109-109 vs., 30 de junho de 1819.

(155). - Idem., 19, f. 101,8 de Junho de 1819 .

(156) . - Idem., 20, f. 127,26 de novembro de 1821 .

(157) . - Idem., 19, f. 198, vs., 23 de fevereiro de 1820.

(158). - Iden., 19, f. 100, 2 de junho de 1819. 